\title{
POPULAR CULTURE OF MISS BEAUTY PAGEANT IN NEPALI CONTEXT
}

\author{
Megh Prasad Kharel*
}

\begin{abstract}
This study examines the Miss Beauty Pageant in the light of popular culture in Nepali context. In the first section, the research attempts to explore different causes of having popularity of Miss Pageant such as rapidly increasing of electronic media, emerging liberal consumer society, glamour politics of physical beauty of the female and gender identity. In the second section, the research discusses two phases of beauty pageant: national-wise and heterogeneous identities based wise (i.e. regional, University, ethnic, caste, professional and institutional wise). In the third section, the article also examines the causes of contradictory opinion from Marxist and feminist force on the contest of the Miss pageant as they underscore the political-cultural side of imperialism, gender discrimination and commercialization of female body, sex and beauty. Despite the opponent voice, the popularity of various beauty contests are increasing day by day. However, specific feature of the pop culture is that it does not distinguish the right and wrong in the overflow of the consumption of the cultural practices. Consequently, opponent circles like Marxists and feminists have almost failed to stop the beauty contest in the consumer mode of Nepali society in the present context.
\end{abstract}

Keywords: Popular Culture, Beauty Pageant, Controversy, Commodification and Nepali Context

\section{History of Miss Nepal and Emerging Liberal Society}

First Miss World Pageant was held at London in 1971. The first Miss American Pageant took place in Atlantic City, New Jersey on 7 September 1921. In the Nepali context, first Miss Nepal Pageant was organized on 7 May 1994. American Miss Pageant became more controversial during the 1960s when the radical feminists "demonstrated in front of Atlantic City's Convention Hall" and "church leaders spoke out against contests" by "threatening contestants with expulsion from church-run schools or participation in the sacraments" (Watson and Martin 8). However, western society is comparatively considered as more consumer and liberal, but the beginning phase of the Miss Beauty Pageant was also questionable and controversial. Similarly, the event of organizing the Beauty Pageant contest in the surrounding of Nepal was also equally controversial as the country is not so liberal, open-minded and consumer in the initial phase.

Nepali society is shifting from feudalistic to more capitalistic lifestyle including the features of fluidity and mutability. It is due to the arrival of various characteristics of modern project such as the globalization, consumerism and advanced information technology as well as unconscious politics of the beauty, sex, nationalism, regionalism, racism and ethnicity. Consequently, the proponents of the Miss pageants are appealing to impress the big media houses, government,

* PhD Scholar of English Language and Literature at Faculty of Humanities and Social Sciences in TU 
industrial men and tourism sector with the purpose of making glamour society more wide, interactive and extensive. At this backdrop, chairman of The Hidden Treasure (THT) - the institute is reputed for organizing the Miss Beauty Pageant in Nepal- appeals with enthusiastically to allure different sectors as he declares, "Now, the time has come to realize and own Miss Nepal as a country's prestige. As such the government, various institutions, tourism sectors and the media should come forward to assist and promote this for the benefit of the nation" (Life 6 Number 9). Indeed, the coordinators, sponsors and organizers of various Miss Pageant contests are reputed businessmen, industrial and NGO/INGOs affiliated personalities. Therefore, their appeal in the favor of Miss Pageants obviously stimulates to the prominent sectors of the state such as government, media, tourism, industry, business and NGO/INGOs.

Two and half decades of practice has passed the organization of Miss Pageant in Nepal. Therefore, Miss Pageant contest is not in the initial phase. It is extending in different phases and sectors. Particularly, there can found two types of Miss Pageant: state-wise/national-wise category of Miss Pageant and heterogeneous identities based Miss Pageants. The state-wise of Miss Nepal pageant has the national identity of Miss Beauty. A Miss Beauty is sorted out in this level has the access and identity of Nepali national or state-wise level. Besides, winners of the Miss Nepal become the representatives and competitors in different international Miss Beauty Pageants such as Miss World, Miss Universe, Miss Earth and Miss Asia pacific. In other words, beauty pageant of state-wise "is not simply, then, about the feminine body, but also about nationalist body" because "the pageant interweaves discourses of feminity with discourses of the national, the body of a beauty pageant contestant is constituted metaphorically" (Banet-Weiser 71). This nationalwise level of the Miss Pageant represents the larger scope of the nation. Therefore, the personality of the Miss Nepal is exalted as a national social body.

Miss Pageant contest is extending in heterogeneous identities in the present days. Such as regional, racial, ethnical, geographical, communal, professional and age-factorial in the context of Nepal are common and getting space in the media and social prestige. Miss Pageant has taken the place in the extensive form, particularly among Nepali mass people after the political change of April 2006 when there occurred a ceasefire between Nepal Government and rebellion Maoist Party. Indeed, the ceasefire, republicanism and secularism has brought more fluidity in the cultural practices of diverse communities. In contrast, the background of Nepali society has the dominant ideological practices of fatalism as Dor Bahadur Bista argues, "the most effect of [this] has been the absolute belief in fatalism; that one has no personal control over one's life circumstances, which are determined through a divine or powerful external agency" (4). Before the republicanism and secularism, "Nepal is fortunate to have a king, a fulcrum of national identity, a marker of cultural continuity" (Dixit 63). Therefore, circumstantial characteristic of Nepali society does not portray so liberal, open-minded and compromising. Anyway, arrival of electronic media, liberal democracy, and republicanism is promoting the popular culture of different categories of Miss Pageant contest in the country as Browne and Pat Browne, critics of popular culture in American context, discusses that such "culture is the voice of democratic, speaking and acting ... It is the everyday world around us: the mass media, entertainments, diversions; it is our heroes, icons, rituals, everyday actions, psychology, and religion—our total life pictures" (7). Obviously then, it has become the lifestyle and lifeblood of different groups without any critical viewpoint, but engaging widely with the purpose of how to use and consume something else. 
The post-conflict, republic and secular state underscore a new generation to be more liberal and open-minded rather than conservative, orthodox and fatalistic. A powerful generation is emerging in the surrounding of no worn shackles of monarchism, feudalism and totalitarianism. For them, various consumer lifestyles like body beauty, sex, cosmetics and dress have become widespread and pervasive. However, the more Nepali society is becoming day by day liberal and openminded, the more performing arts and beauty concert activities such as dancing, singing, modeling, and performance professions have also become safety and prestigious. Consequently, body beauty, sex, cosmetics and dresses have played the vital role in the consumer mentality of the mass people. The mindset of the middle class allows "a utilitarian justification beyond simple escapist, frivolous entertainment or pleasure" (Liechty 185). At this backdrop, Miss Pageant has become more persuasive and prestigious to the middle class in the urban area of the society. As a consequence, organizing and celebrating of various Miss Pageants contest are also enhancing the process of consumer way of thinking among the Nepali mass people.

Jarah Banet-Weiser has studied the American context of the Miss American Pageant and also opines that "mid 1990s in the United States were characterized by public recognition of "identity politics" (67). The discourse of the identity politics in Nepali context took the place since postconflict time. In addition, the post-conflict Nepal is booming with various identities based Miss Pageants like regionalism, ethnicity, racism, community, professionalism and age-factor. Accordingly, Miss Pokhara, Miss Chitwan, Miss Kathmandu, Miss Purbanchal, Miss Teenage, Miss College, Miss University, Miss Journalist, Miss Newa, Miss Tamang, Miss Mustang, Miss Sherpa and Miss Beautiful are common expressions in the Nepali media. But Miss Nepal is only considered as a national wise based Miss Pageant contest. Similarly, television and electronic media are highlighting the commodification of contestant body beauty and personality. In this regard, winner and successful in the contest of Miss Nepal is fetishized as a Helen Beauty by using the social mass media and culture.

\section{Glamour of Physical Beauty and Hidden Talent}

Adorning the crown of the prestigious beauty Miss Nepal has become a dream for a number of young middle class related Nepali women. Moreover, it also provides the wider scope to get the better opportunity in the glamour world. Regarding the glamour politics of the body beauty among Beauty pageants, Iset Anuakan argues,

Beauty pageants are the human forums in which girls become true to life princess. The narratives in twenty-first-century pageants, where a winner is crowned, follow a similar pattern as that in many folktales ... the aspects of female competitions that provide opportunities to advance economically are consistent with centuries of mythmaking in the princess literature. (116)

Furthermore, the proponents and organizers are also making the propaganda of getting the opportunities of economically advanced and social prestige better. Such propaganda is making middle class women more ambitious and motivated to engage in the beauty contests in different phases and levels. At this backdrop, Ruby Rana, first Miss Nepal in the history of Beauty Pageant, also finds the wider scope and career after getting the success of Beauty contest as she opines, "The title of Miss Nepal broadened me to choose the options . . In the beginning I was a 
common girl of Birganj. I came Kathmandu being a Miss Nepal. I got opportunity to visit various countries. So I often feel that I contributed something in the glamour arena" (Kamana 9). In the same way, Shweta Singh, 1999's Miss Nepal, is campaigning in the favor of Miss Pageants as she opines: "Those who were crowned after her have a wider scope for Miss Nepal nowadays (8)." Likewise, Hidden Treasure also focuses on the wider scope in the career of Miss Beauty Pageant because it is more concerned with glamour of fashion designs, empowering women and engaging in social service. However, the objective of Miss Nepal has two pillars: "personality and leadership development" (Tht Life 7). The organizers claim that they do not only focus on beauty of the body, but also personal talent and leadership development of the lady. It seems that the organizers and sponsors are basically focusing on the developing personality. Such personality should combine "beauty, brain, confidence, positive mind and one who will be able to represent Nepal as its worthy ambassador to the outside world. A strong Miss Nepal must also possess interests in issues relating to empowering women, engage in social service and in promoting issues related to women" (11). In addition, the organizers teach them that Miss Pageant contest is an amazing journey of beautiful young ladies for the purpose of their developing the personality of confidence and assuredness in the glamour world.

\section{Sponsors and Glamour Politics in the Miss Pageant}

The glamour politics of the beauty world enhances the reproduction, commercialization and commodities. In other words, sponsors and investors want to utilize the physical beauty of the women as they sell maximum of their productions and commodities in the market to get the profits. They highlight the physical beauty of the new and energetic women, who are used in advertisements, hoarding boards, pamphlets, posters, speech, slogan and procession. Among the sponsors and investors, Shree Ganapati Jwellers was one of them in Miss Nepal 2014. This business company sells a variety of items like diamond, gold, silver and astral gems. It uses poetic and melodious lines of the beauty women in the hoarding board of an advertisement. Like the Shree Ganapati Jwellers, other sponsors and co-sponsors of the Miss Nepal 2014 are DECC UWTC (Tripureshwor), Prisma Advertising Agency (Kalikasthan), Jaya Furnisher (Dillibazar), Supply Solution P (Ltd) (Sanepa), Chameli Nursery (Jhamsikhel), Radisson Hotel(Kathmandu), Nepal Army Officers' Club (Bhdrakali), JCI Kathmandu (Naya Baneswor), Music Designer: Dj Vital-Vital Records, Nepal Trust for National Conservation, World Wildlife Fund,(Baluwatar), Maiti Nepal (Gaushala), Nanglo Café and Pub (Durbarmarg), Russian Culture Center (Kamal Pokhari), International Union for Conservation of Nature (Kupondole), Coca-Cola Company, Samsung Galaxy Grade 2 and the like (The Life, Issue 7 57-59). Various agencies from the business houses, industries and institutions are sponsoring to different Miss Pageant contests for the purpose their promoting such glamour politics in the large scope of urban and marketplace.

\section{Polarization of Nepali Intellectuals}

Adorning the crown of the Beauty Pageants like Miss Nepal, Miss Pokhara, Miss University and Miss Newa is a dream for a number of young middle class lady in Nepal as they think it is a

${ }^{1}$ The quoted lines and materials from Nepali language in this article are my own translation. 
prestigious and prominent position in the urban life as well as betterment of the future career in the glamor world. In contrast, the opponent force of the Miss Pageants in the Nepali society has also equally strong, powerful and effective. The left force has the strong grass- root in the politics in Nepali context. Therefore, left intellectuals and Marxist feminist have the oppositional view to organize the beauty pageants and they severely criticize such contests.

There are three types of group among Nepali intellectuals who look the Miss Pageants in different ways. First, anti- Miss Pageant intellectual force, whose views are completely counter-attack of all kinds of Miss Pageants. Such category of intellectual group is more related to Marxists, Marxist feminists and feminists, who completely go against the Miss Pageants. Second, centrist or moderate intellectual forces, who think that Miss Pageant is partially right and wrong. Some liberal Marxists, democratic force and other independent intellectuals have such centrist and moderate notion about the Miss Pageant. Third kind of intellectual force is such a group who entirely supports and sponsors to the Miss Pageants. Such category of intellectual force is actively involved in different pageants. Big media houses, urban elites and commercial mentality related middle class intellectuals promote such activities in different levels of Miss Pageants.

Nepali Marxist intellectuals have created different narratives in the market about the Miss Pageant Beauty contests. They raise the question against Miss Pageant by putting different logical appeals such as the Miss pageant as a misuse of the lady by the big media houses, industries, business companies and multinational companies. It is also the commodification of the women's body beauty in the capitalist society; judgment of the personality and talent in the pageant is farcical; fashion, sex, cosmetics and body beauty of the lady treat the woman as a commodity in the capitalist and patriarchal society; it never portrays the social, cultural, national and ethnical identity rather it defames the social status in the human civilization. However, fashion, cosmetics, sex and the body beauty of the lady are the consumer mentality of the patriarchal and capitalistic society. It is not a consequence of the women right and freedom, but it behaves the lady like a commodity of the market where a customer can buy according to own utility because entrepreneurs and industrial persons are the sponsors and investors of the Miss lady and they buy her body beauty according to their utilitarian strategy. Consequently, such narrative was comparatively strong in the initial phase of Miss Pageant in Nepali context, but now it comparatively loosing such voice in the spaces of big and social media.

Ninu Chapagai, one of the influential anti- Miss Pageant intellectuals and reputed Marxist critic, criticizes all kinds of Miss Pageant contests and argues that its internal network is directly associated with " economic system of the imperialism" (139). Imperialism is the highest level of capitalistic system and its typical tendency enhances the "profit of the capitalists" (140).

Therefore, Chapagai claims that various "capitalists and profiteers" are not paying the attention to produce the "qualitative and beauty commodities." Through the propaganda of body beauty of the woman, they forcefully create "illusion of the beauty" in the mass society. Moreover, he also emphasizes that the rationale of the Miss Pageant is to produce the "models production" through the "advertisement" in the "capitalistic consumerism" (141). Consequently, "makeup, dress, walking, eating style, dance, personality development and so many factors are highlighted" in the contests of Miss Pageant. Among the competitors, the first Miss Pageant is selected. Her body beauty, fashion show and cosmetics are given priority for the propaganda in the social medias and big media houses. The "external body beauty of the women" is underscored, but "internal beauty like intellectuality, wisdom and honesty" of the woman are ignored in the process of contest. 
Therefore, Chapagain contends that both "patriarchal and capitalist mentalities" have fusion in the contest for the purpose of taking the benefit by the commodification of body beauty of the woman. Similarly, Amar Giri contends that "beginning phase of the Miss Pageant was purely associated with the physical beauty of the woman, but now it has linked with talent" (9). But Giri harshly critiques the Miss Pageant and says that it is "an attractive process of the women objectification, but not the link with the talent of them" (10). In addition, he claims, "Marxists are not anti-beauty, but Miss Pageant is only ended with capitalistic profit, utility and materialistic desire" (11). Likewise, another Marxist critic Sukum Sharma also raises the question on the ethical issue as he articulates, "The manliness has a scarce in the Miss Pageant and wicked sensory is exposed because physical pleasure is inspired rather than wisdom" (14). Emphasizing his disapproval of organizing Miss Pageant contest, Harigovind Luitel asserts, "It is a process of imprisoning the beauty of the women in prostitution" (14). In the same way, Sudha Tripathi, a Nepali Marxist feminist writer, underscores the issue of gender discrimination in the contest program of Miss Pageant and she further emphasizes, "There is running a business of the bargaining of the heap meat in the name of Miss Pageant in the patriarchal and capitalist society" (104). However, Hisila Yami, female politician from the background of ex-Maoist Party, argues that "capitalists are cleverly using the beauty body, appearance, youth and smile of the women in their business competition in the Miss Pageants" (35).

Liberal Marxists, democratic force intellectuals and other some independent intellectuals have the centrist or moderate view in the case of Miss Pageant. Narayan Dhakal, as a liberal Marxist writer, insists that Miss Pageant is partially right and wrong. Moreover, he discusses that judgment of the personality and talent of the women in the Miss Pageant cannot be ignored, but tremendous commodification and exploitation of the body beauty of woman $b$ different business houses should be opposed ${ }^{2}$. His perspective is that every Miss Pageant does not involve the purpose of commodification and profit of the women body beauty because identity based Miss Pageants has no dominant desire of the profit and commodification. At this point, Dhakal explains that various rural background of people, schools, colleges and universities are also organizing Miss Pageants and they have no such extreme concern of profit and marketization. In this sense, his claim is that all kinds of the Miss Pageants have not political desire of economical imperialism and capitalistic concern, but they have also created own personal, regional, social and cultural identity.

Demonstrations against Miss Nepal were rife from the Marxist intellectuals, feminists and Marxist feminists in the beginning phase. In 2004, Nepali left writer Khagendra Sangraula has led Anti-Miss Nepal demonstration in Kathmandu valley. According to Harigovind Luitel, "almost eight organizations were involved in that campaigning" in the demonstration (11). As a consequence, such intellectuals have critical thoughts and opinions about Miss Pageants, but the glamor politics and its popular culture of Miss Beauty Pageants are spreading day by day in the Nepali society.

${ }^{2}$ My talk with Narayan Dhakal 


\section{Conclusion}

Indeed, heterogeneous identities of Miss Pageants are rife in the Nepali society, ranging from urban to city, rural to town, school to university, regional to national and racial to ethnic communities. However, it has become difficult to stop their organizing because it is extending day by day as a mode of popular culture. It is massively impacting to the mass people as mass culture has no critical viewpoint to say its wrong and right outcome. In the intellectual circle, some of the Marxists and feminists are severely condemning as they claim that such contest is promoting commodification of the woman beauty and sex. Second group have the moderate views of the intellectuals, who are not entirely ruling out the Miss Pageants, but they favor the positive aspect of the contest. In the same way, third group of the middle class urban people are blindly supporting the Beauty Pageants. Actually, the discourse of the Miss Pageants is focused on the issues of beauty, sex, body, commodification, personality development and talent of the women. Since few years ago, the voice of the oppositional force is diminishing as the popular culture of the Miss Beauty is extending from national -wise/state -wise to heterogeneous identities of ethnical, regional, University, caste and racial wise.

\section{Works Cited}

Anuakan, Iset. "Princess Literature and the Miss America Pageant." The Politics of Sex, Beauty, and Race in American's Most Famous Pageant. Palgrave Macmillan, 2004. 111-124.

Banet-Wester, Jarah. "Miss America, National Identity, and the Identity politics of Whiteness." The Politics of Sex, Beauty, and Race in American's Most Famous Pageant. Palgrave Macmillan, 2004. 67-89.

Bista, Dor Bahadur. Fatalism and Development: Nepal's Struggle for Modernization. Orient Blackswan, 2011.

Browne, Ray B and Pat Browne. "The Generalities of Cultures." Profile of Popular Culture: A Reader. University of Wisconsin Press, 2005. 1-13.

Chapagai, Ninu. “Sundaripratiyogita Ke Ho ra Kina Garinchcha?” Sandarbha: Sanskriti ra Sanskritik Rupantaran. Bibek Srijanshil Prakashan, 2003. 130-156.

Dixit, Kanak Mani. “A New King and the Challenge of Democracy.” State of Nepal. Eds Kana Mani Dixit and Shastri Ramachandaran. Himal Books. 62-76.

"Poorba Miss Nepalharooko Chiyo-Charcha." Kamana Magazine. Kamana Printing and Private Ltd., 2054 (Year 13, No. 6 112). 8-9.

Giri, Amar. "Miss Pageant: Illusion and Reality (Sundari Pratiyogita : Bhram Ra Bastabikata)." Samay, Samaj ra Sanskriti. Bibek Srijanshil Private Ltd, 2011.9-14.

"History: Miss Nepal." Tht Life Vol 1 Issue 7 Miss Nepal 2014. Ed. Subarna Chhetri. THT Publication, 2014. 10-11.

Kakshapati, Gopal Sundar Lal. Tht Life Vol 1Number 6 Miss Nepal 2013. Ed. Subarna Chhetri. THT Publication Pvt. Ltd, 2013. 
Liechty, Mark. Out Here in Kathmandu: Modernity on the Global Periphery. Martin Chautari Press, 2010.

Luitel, Harigovind. "Sundari Pratiyogita: Baadbibaad." Nawa Yuwa: A Monthly Magazine for the Youth. Mulyankan Prakashan Griha, 2004 (Aug-Sept) pp. 8-14.

Sharma, Sukum. "Sundari Pratiyogitako Seroferolai Khotalda." Sandhyakali Daily Magazine. Naya Morcha Publication, 1998 (March 15) pp.14.

Tripathi, Sudha. "Saundarya Pratiyogitama Jhalkiyeko Biraat Kurupata)." Chelibetika Beglai Kura. Bhrikuti Academic Publication, 2012. 102-104.

Watson, Elwood and Darcy Martin. The Politics of Sex, Beauty, and Race in American's Most Famous Pageant. Palgrave Macmillan, 2004.1-23.

Yami, Hisila. "Hisila Yamiko Antarwārtā.” Mulyankan Monthly Magazine. Mulyankan Prakashan Griha, 1996 (September) Year 13, Purnanka 32.34-35. 